\title{
Argumentation for critical parameters and operating modes in the process of underwater mining of placers
}

\author{
Farzad Fatehi $^{1}$, Yevhen Semenenko ${ }^{2}$, Olha Medvedieva, ${ }^{2,}$, Larysa Tatarko ${ }^{3}$, and Olexander \\ Haminich $^{4}$ \\ ${ }^{1}$ University of York, YO10 5DD, York, United Kingdom \\ ${ }^{2}$ Institute of Geotechnical Mechanics named by N. Poljakov of National Academy of Sciences of \\ Ukraine, 49005, Dnipro, Simferopolska Str., 2a, Ukraine \\ ${ }^{3}$ Ukrainian State University of Chemical Technology, Haharina Ave., 8, Dnipro, 49600, Ukraine \\ ${ }^{4}$ Oles Honchar Dnipro National University, 49000, Dnipro, Haharina Ave., 72, Ukraine
}

\begin{abstract}
The purpose of the article is to study the connection between the parameters of the formation of the suction funnel, such as the scattering speed and concentration of the suction mixture, and the concentration of the slurry in the suction pipe, which provides supercritical flow conditions. This connection is considered in terms of the most common process of underwater mining of placers for the open mining technology by suction dredger. The importance of the research is conditioned by the well-known but not yet thoroughly studied phenomenon of a decrease in the performance of the dredger pump on solid material without breaking the vacuum, which in most cases leads to a hydraulic shock in the pressure line. It is argued that the cause of this occurrence is the onset of a critical flow regime in the suction pipe due to inconsistency of the parameters of the hydrotransport modes and suction funnel formation. A combined analysis of the known dependences for the critical rate of hydro transportation in an inclined pipeline and for the geometric parameters of the suction funnel made it possible to establish restrictions on the concentration of solid particles on the surface of the erosion funnel.
\end{abstract}

\section{Introduction}

A significant part of alluvial deposits in Ukraine is watered or located under a layer of water. Such deposits include not only man-made placers formed in storage facilities for mineral processing enrichment waste, but also primary placers of polymetallic ores [1 - 4]. Most of primary placers located under a water layer and almost all technogenic placers are developed using dredgers by suction without preliminary loosening by milling cutters and weighing by water jets [5 - 7] Historically, pre-loosening and underwater erosion technologies have become widespread when used for clearing fairways and dredging measures on river beds and also in the process of washing dams and constructing other hydraulic structures $[5,8]$.

\footnotetext{
*Corresponding author: medvedevaolga1702@gmail.com
} 
Even the first attempts to use dredgers for the extraction of placers without the use of special devices for preliminary weighing of the extracted material revealed differences in their operating modes compared to dredgers used on rivers and reservoirs $[1-3,5,7]$. Hence, the frequent water hammer caused by the inability of the pump to raise the hydraulic mixture through the suction pipe was noticed even in cases when the pressure at the pump inlet exceeded the permissible values for the receipt margin [1 - 3]. Back in that period of time the researchers had observed and recorded this phenomenon, but they did not find the causes of its occurrence, so they could not provide the possible solutions. At the beginning of the XXI century, when man-made concentrators of the Kryvbas (Kryvorizkyi Iron Ore Basin) began to actively develop man-made placers accumulated in waste storage, the scientists encountered this phenomenon again and the issue of substantiating critical parameters and operating conditions in the process of underwater mining of placers became vital $[8,9]$.

Efficient underwater development of alluvial deposits involves the coordination of suction and hydrotransport modes, which ensures stable operation of the dredger. It also demands to determine the time for the development of a particular site of the placer considering the diameter of the suction pipe, the size of the particles of the placer and the distance between the surface of the placer and the inlet to the suction pipe. There are already known methods that are used for calculating the diameter of the suction funnel that take into account the diameter of the pipeline, erosion rate and flow rate $[5,7]$. However, these methods do not allow to determine the concentration of the slurry absorbed, which makes it difficult to calculate the time of the erosion funnel formation and the productivity of the dredger on solid material. Moreover, the known methods do not take into account that the process of flow of the hydraulic mixture in the suction pipe has its own characteristics, in particular, it is limited by the critical rate of hydraulic transport. When a flow rate exceeds a critical point the slurry moves as a homogeneous liquid of increased density. When the critical rate is reached, the slurry flow in the inclined pipeline is stratified, the solid particles are concentrated in the bottom dense, pulsating layer, and water moves over this layer.

Thus, the aim of our research is to establish a relationship between the parameters of the formation of the suction funnel, such as the scattering speed and concentration of the suction slurry, and the concentration of the slurry in the suction pipe, which is necessary for supercritical flow conditions.

\section{Methods}

The capacity of the dredger to absorb solid particles is limited by the hydraulic resistance of the suction line, the receipts of the pump that is used and the critical speed of hydrotransport, which depends on the diameter of the pipeline, hydraulic size and density of the particles of the placer, and also on the concentration of the slurry $[1,10-12]$ :

$$
V \geq V_{c r}
$$

where $V_{c r}$ is the critical speed of hydro transportation, mps [1, 11]; and $V$ is the average flow rate of the flow of the slurry, mps.

The prior use of hydro mechanization technologies for the development of primary and technogenic placers indicates a restriction of the concentration of suction slurries $[1,2,8]$ :

$$
C<C_{m},
$$




$$
C_{m}=\frac{0.2 \rho_{S}}{\rho_{S}-\rho_{W}},
$$

Which in its turn allows us to use the following formula to calculate the critical rate of hydrotransport in an inclined pipeline $[1,2,8]$ :

$$
\begin{gathered}
V_{c r}=15 \frac{0.6+0.08 c}{1-0.2 c} \sqrt[3]{D} \sqrt[4]{w} \cos \alpha, \\
c=\frac{C}{C_{m}}
\end{gathered}
$$

where $C$ is the mass concentration of the slurry; $c$ is the relative mass concentration of the slurry; $C_{m}$ is the boundary value of mass concentration for low concentration hydraulic mixtures $[1,13] ; 15$ is the empirical coefficient, $\mathrm{m}^{5 / 12} / \mathrm{s}^{3 / 4}[1,2,8]$; $D$ is the pipeline's diameter, $\mathrm{m} ; w$ is the average hydraulic size of the transported material, mps; $\rho_{S}$ is the

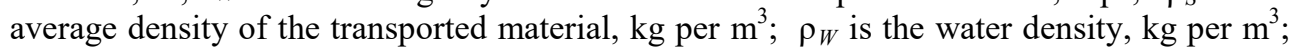
$\alpha$ is the angle of inclination to the horizon of the suction pipe of the dredger.

By inserting the formula (4) into the assumption (1), while previously having rearranged them according to equations (2) and (3), we arrive at a conclusion that the restrictions of the dredger's ability to absorb solid particles in the critical hydrotransport speed can be represented as the following inequation:

$$
\begin{aligned}
& c \leq c_{c r}, \\
& c_{c r}=5 \frac{\rho_{*}-0.6}{\rho_{*}+0.4}, \\
& \rho_{*}=\frac{V_{D}}{15 \sqrt[3]{D} \sqrt[4]{w} \cos \alpha},
\end{aligned}
$$

where $c_{c r}$ is the relative mass concentration of the slurry for which the rate will be critical for a given suction pipe; $\rho_{*}$ is the dimensionless absorption rate; $V_{D}$ is the speed in the suction pipe, mps.

The number of particles in the transverse inlet section of the pipeline, given the flow rate and the concentration of the slurry, as well as the diameters of the suction pipe and of anthropogenic placer solid particles, can be presented by the following formula:

$$
n_{D}=\frac{C}{\delta^{2}}, \quad \delta=\frac{d_{a V}}{D},
$$

in which $n_{D}$ is the number of particles in the transverse inlet section of the pipeline; $d_{a v}$ is the weighted average particle diameter of the erosive material, $\mathrm{m} ; \delta$ is the relative particle diameter of the erosive material.

It is evident that the dredger is able to suck in only a certain quantity of particles under condition that this quantity will not create the critical flow regime in the suction pipe.

For the slurry of examined concentration, taking into account the formulas (2) and (3), the assumption can be represented as the following inequation:

$$
n_{D} \leq n_{c r},
$$




$$
n_{c r}=5 \frac{\rho_{*}-0.6}{\rho_{*}+0.4} \frac{C_{m}}{\delta^{2}}
$$

where $n_{c r}$ is the number of particles in the transverse inlet section of the pipeline under the critical flow regime.

Considering the suction funnel as a segment of a sphere (Figure 1), according to the results of the experimental studies $[1,7,11]$, we can assume that the volume of solid particles will be calculated by the formula:

$$
W_{P}=\frac{4}{3}(1-m) \pi h^{3}
$$

while the number of particles in this volume will equal:

$$
n_{P}=8(1-m)\left(\frac{h}{d_{a V}}\right)^{3}
$$

where $W_{p}$ is the volume of solid particles in the erosion funnel, $\mathrm{m}^{3} ; n_{p}$ is the quantity of particles in the volume of the erosion funnel; $h$ is the diameter of the washout funnel at the level of the inlet section of the suction pipe, $\mathrm{m} ; m$ is the porosity of the industrial placer.

The diameter of the erosion funnel according to the level of the inlet section of the suction pipe and according to the experimental data of famous authors $[1,7,11]$, is determined by such conditions as the diameter of the pipe, the rate of erosion and the flow rate of the slurry.

$$
h=\frac{D}{2} \sqrt{\frac{V_{D}}{2 V_{P}}},
$$

where $V_{p}$ is the erosive rate, $\mathrm{mps}[7,11]$.

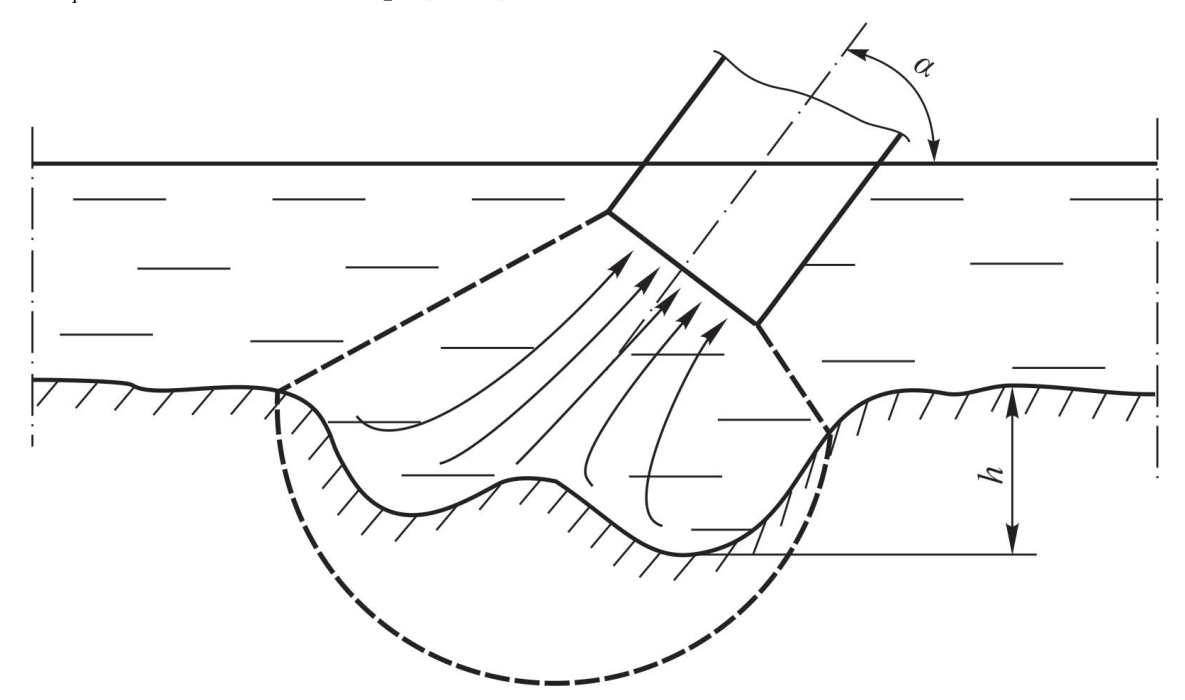

Fig. 1. Suction funnel formation pattern.

By inserting the formula (14) into equations (12) and (13), we obtain: 


$$
\begin{aligned}
& W_{P}=\frac{1-m}{5.4} D^{3}\left(\frac{V_{D}}{V_{P}}\right)^{\frac{3}{2}}, \\
& n_{P}=0.354 \frac{1-m}{\delta^{3}}\left(\frac{\rho_{*}}{U}\right)^{\frac{3}{2}}, \\
& U=\frac{V_{P}}{15 \sqrt[3]{D} \sqrt[4]{w} \cos \alpha},
\end{aligned}
$$

where $U$ is the dimensionless erosive rate.

The process of formation of a suction funnel will come to an end when all the particles contained in the volume of this funnel fall through the suction pipe into the hydrotransport line. But, according to condition (10), only a limited amount of solid particles can pass through the suction pipe. Thus, the duration of the formation of the suction funnel and the concentration of the suction slurry, are determined by the ratio of $n_{p}$ and $n_{c r}$.

If $n_{p}$ does not exceed $n_{c r}$, then :

$$
n_{c r} \geq n_{P}
$$

In this case the process of forming a suction funnel occurs without the emergence of a critical flow regime in the suction pipe of the dredger. Thus, a combined consideration of formulas (9), (16) and (8) allows us to obtain an equation for calculating the concentration of the suction slurry:

$$
C=0.354 \frac{1-m}{\delta}\left(\frac{\rho_{*}}{U}\right)^{\frac{3}{2}} \text {. }
$$

For this concentration and a given rate in the suction pipe $V_{D}$, the dredger is capable to pump the volume of soil completely in the time determined by the following formula:

$$
T=\frac{W_{P}}{C \frac{\pi}{4} D^{2} V_{D}},
$$

where $T$ is the erosion funnel formation time, $\mathrm{s}$.

By inserting the formulas (15), (19) and (8) into the formula (20), we transform the equation for calculating the time of funnel formation into the following form:

$$
T=\frac{3}{2} \frac{d_{a V}}{V_{D}}
$$

If in this case the meaning of $n_{p}$ is more significant than $n_{c r}$, we obtain:

$$
n_{c r}<n_{P}
$$

So, then the flow passing through the suction pipe cannot immediately deliver to the pump the entire volume of particles that are contained in the erosion funnel. And therefore the slurry with a relative concentration close to the critical value will enter the suction pipe: 


$$
c=k \frac{\rho_{*}-0.6}{\rho_{*}+0.4} 5
$$

where $k$ is the experimental coefficient that takes into account the difference in the actual concentration of the slurry from the critical value $(k>1)$ [1].

When condition (22) is fulfilled, the time of formation of the erosion funnel will be determined not only by the value of the suction rate, but also by the value of the erosion rate:

$$
\begin{aligned}
& \frac{T}{T_{*}}=0.047 \frac{1-m}{k C_{m}} \frac{\Omega}{\sqrt{U^{3}}}, \\
& \Omega=\frac{\rho_{*}+0.4}{\rho_{*}-0.6} \sqrt{\rho_{*}}, \\
& T_{*}=\frac{\sqrt[3]{D^{2}}}{15 \sqrt[4]{w}},
\end{aligned}
$$

where $T_{*}$ is the time of the erosion funnel formation process, $\mathrm{s} ; \Omega$ is a dimensionless complex.

Thus, the equations (3) - (26) allow us to calculate the maximum permissible concentration of the slurry in the suction pipeline according to physical properties of the slurry, the geometric characteristics of the suction pipeline and the technological parameters of the production process. This concentration will eventually enable us to avoid reaching the critical flow regime at a given pump performance. These dependencies for the first time take into account the influence of the ratio of suction rate and erosion rate on the concentration of slurry and the time of the formation of the erosion funnel.

\section{Results and discussion}

The possible intervals of values change that are included in formulas (3) - (26) are determined by the actual existing intervals for changing the critical value of the relative concentration of the slurry. Namely, according to the formula (7), this value cannot be less than zero and more than one (Fig. 2):

$$
0.6<\rho_{*}<0.85
$$

The Figures 3 and 4 represent the results of calculations according to the formulas (23) and (25) for the possible change intervals of values.

By analyzing the Figures 3 and 4 and equations (23), (24) and (25) for the extreme points, we observe that the dependences of the relative concentration of the slurry and the time of the erosion funnel formation reach their maximum and minimum values at the boundaries of the variation interval in the dimensionless suction rate (27). Whereby, the relative concentration of the slurry increases steadily from zero to $1 / 4$ of its maximum value with an increase in the suction rate. Meanwhile the time of the erosion funnel formation in its turn does not decrease proportionally. The most meaningful decrease in the time of the suction funnel formation is observed at values of the dimensionless suction rate that are not exceeding 0.65 .

As a result of analyzing the formulas (3) - (26) we can arrive at the following conclusion: there is a possibility of carrying out the processes of slurry suction and the erosion funnel formation in two different modes. The first one is conducted when condition (18) is fulfilled, 
which means that the slurry enters the pump without causing critical flow regime in the suction pipe. In this flow regime the concentration of the slurry does not exceed the critical value and is determined by the ratio of the suction rate to the erosion rate to the degree of $3 / 2$. The erosion funnel formation time in this mode is proportional to the ratio of the particle diameter of the extracted material to the suction rate. While the second mode is conducted when condition (22) is fulfilled. Thus, when the slurry enters the pump it leads with high probability to creating a critical flow regime in the suction pipe. In this mode, there is an excess of solid particles in the area of erosion funnel formation since these particles enter the suction pipe with a concentration close to the critical value. It should be mentioned that in the second mode the concentration of the slurry is determined by the value of the dimensionless suction rate and does not depend on the value of the erosion rate. Also, the time of the erosion funnel formation is determined by the values of the suction and erosion rate.

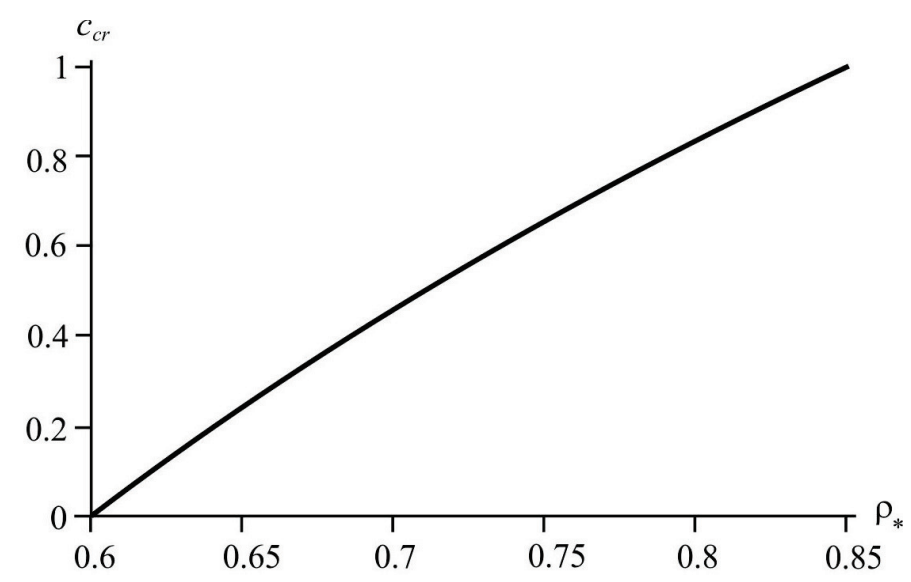

Fig. 2. The dependence of the critical value of the relative slurry concentration on the dimensionless speed in the suction pipe.

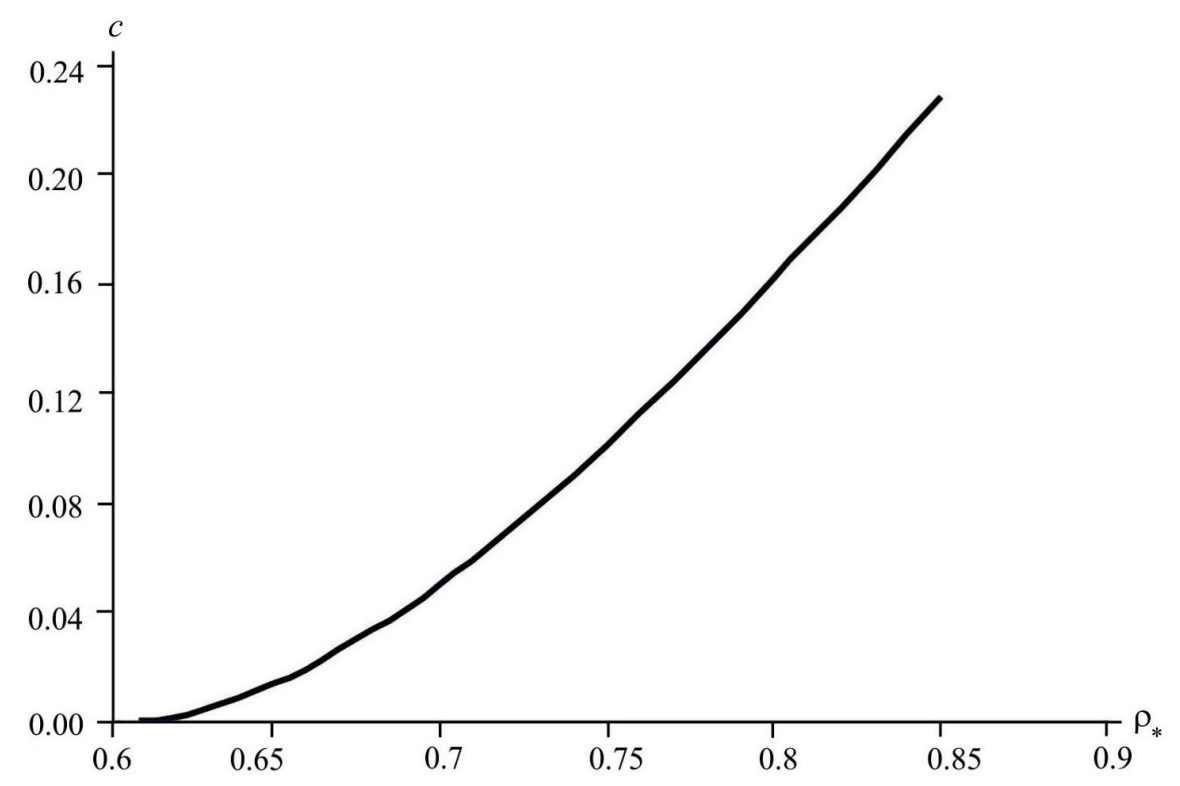

Fig. 3. The dependence of the relative concentration of the slurry in the suction pipe on the dimensionless speed in the suction pipe for the low concentration slurries. 


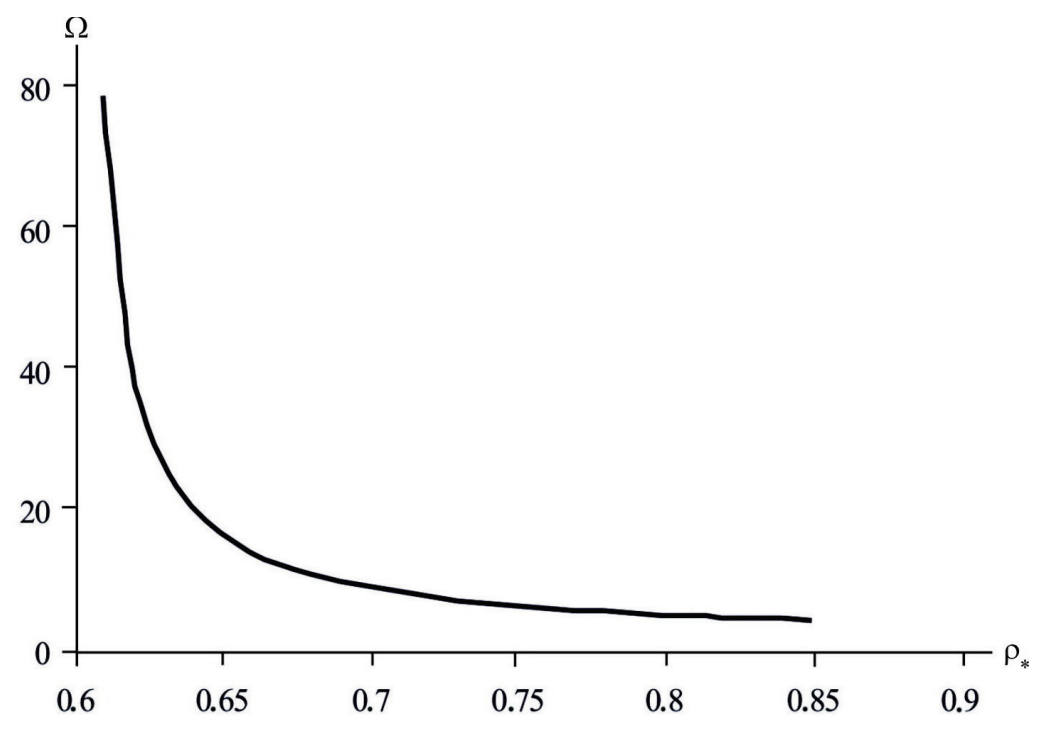

Fig. 4. The dependence of the parameter $\Omega$ on the dimensionless speed in the suction pipe for the low concentration slurries.

\section{Conclusions}

The results of the research allow us for the first time to calculate the maximum permissible concentration of the slurry on the surface of the suction funnel, without causing a critical flow regime in the suction pipe for the given pump performance. This concentration is calculated considering the physical properties of the placer, the geometric characteristics of the suction pipe and the production process parameters.

The proposed dependences for the first time take into account the effect of the ratio of the critical suction and erosion rate on the concentration of the slurry. Our research proves that the value of the maximum possible concentration of slurry on the surface of the erosion funnel is determined by the product of the dimensionless washout rate and the function of the dimensionless critical suction rate. The nature of this function is determined by the interval of variation in the concentration of the slurry. For slurries of the considered concentration it is characterized by a steady increasing dependence, when the maximum and minimum concentration values are reached at the boundaries of the interval of variation in the suction rate.

The validity and reliability of these results are determined by the exactitude of the problem that we search a solution for, the use of proven methods of hydraulics, hydromechanics, as well as postulates confirmed by the results of experimental research of other authors in this field of study.

Thus, we argue the maximum possible concentration of solid particles, selected by the flow from the surface of the suction funnel, which provides supercritical flow in the conditions of underwater extraction of placers using dredgers by suction without preliminary loosening and underwater erosion.

\section{References}

1. Semenenko, Ye.V. (2011). Nauchnyie osnovyi tehnologiy gidromehanizatsii otkryitoy razrabotki titan-tsirkonovyih rossyipey. Kiev: Naukova dumka 
2. Baranov, Yu.D., Blyuss, B.A., Semenenko, Ye.V., Shuryigin, V.D. (2006). Obosnovanie parametrov $i$ rezhimov rabotyi sistem gidrotransporta gornyih predpriyatiy. Dnepropetrovsk: Novaya ideolohiya

3. Maharadze, L.I., Gochitashvili, T.Sh., Kril, S.I., Smoylovskaya, L.A. (2006). Truboprovodnyiy gidrotransport tverdyih syipuchih materialov. Tbilisi: Metsniereba

4. Gumenik, I.L., Sokil, A.I., Semenenko E.V., Shurygin, V.D. (2001). Problems of development of placer deposits. Dnepropetrovsk: Sich

5. Yaltanets, I.M. (2006). Hydromechanized and underwater mining. Moskva: Mir gornoy knigi

6. Bulat, A.F., Vitushko, O.V., Semenenko, E.V., (2010). Models of elements of hydraulic systems of mining enterprises. Dnepropetrovsk: Gerda

7. Bondarenko, A.A. (2018). Modeling of interaction of inclined surfaces of a hydraulic classifier with a flow of solid particles. Naukovyi Visnyk Natsionalnoho Hirnychoho Universytetu, 4, 13-20. DOI: 10.29202/nvngu/2018-4/5

8. Semenenko, E.V. Medvedeva, O.A. (2015). Hydrodynamics of pressure-bearing suspended flows: history and prospects. Geotehnicheskaya mehanika [Geo-Technical Mechanics], 124. $289-302$

9. Semenenko, Ye., Nykyforova, N., Tatarko, L. (2015). The features of calculations of hydrotransport plans of geotechnological systems. Theoretical and practical solutions of mineral resources mining. London: Taylor \& Francis Group, 397 - 401

10. Poturaev, V.N., Voloshyn, O.I., Ponomarev, B.V. (1989). Vibratsionnopnevmaticheskoye transportirovaniye sypuchikh materialov. Kiev: Naukova dumka

11. Kril, S.I. (1990). Pressure flow. Kiev: Naukova dumka.

12. Voloshyn, O.I., Ponomarev, B.V. (2001). Mechanics of pneumatic conveying of bulk materials. Kiev: Naukova dumka

13. Semenenko, E.V., Medvedeva, O.A., Kirichko, S.N., Tatarko, L.G. (2018). Features of calculating the parameters of highways for hydromechanization technologies in the conditions of enrichment waste storage. Geotehnicheskaya mehanika [Geo-Technical Mechanics], 140, $118-129$ 